\title{
Planning of Production, Inventory and Logistics with Direct Shipment and Milk run Strategies: Numerical Experiment
}

\author{
*Pacharawan Suebsangin, Naruemol Ratanamalakul and Aussadavut Dumrongsiri \\ Thammasat University, Bangkadi Campus, PathumThani, Thailand \\ *pacharawan.ploy@gmail.com
}

\begin{abstract}
We study a supply chain comprised of a manufacturer owning multiple production lines and a warehouse, and multiple retailers buying from the manufacturer. The manufacturer can choose whether to send products to the retailers directly from loading area using direct shipment or send the product to be stored at the warehouse. If the demand is satisfied from the warehouse, the company can choose the logistic strategy. The company can send the product from the warehouse to a retailer using a direct shipment mode (a truck only visits the retailer) or using milk run mode (a truck visits multiple retailers in a single trip). We develop a mixed integer programming model to find the optimal decisions for production quantities at each production line, the quantities of inventories at the loading area, the warehouse and the retailers, and the transportation strategies to deliver products to retailers in every period. We conduct numerical experiments and then analyze the results. Many managerial insights are drawn for practitioners. Several optimal transportation strategies are observed by mixing between a temporal demand aggregation strategy, the milk run strategy and the direct shipment strategy.
\end{abstract}

Keywords: Supply Chain Management, Logistics, Milk run, Optimization, Mathematical Model

\section{Introduction}

Transportation cost becomes an important issue for every business because it is the main proportion of logistics cost. Most firms are organized into a network of manufacturing and distribution sites from importing the raw materials, processing them into finished goods, and delivering the finished goods to customers. The inventories exist throughout the supply chain as raw materials, work-in-process, or finished products causing the inventory holding cost. To minimize the operational cost, a company must synchronize all the planning of production, inventory and distribution strategies at the same time. Many distribution strategies exist to help company reduce the cost. A direct shipment, a direct transport of finished product from a manufacturer to a retailer without stopping at any intermediate facility, can help reduce the logistics cost, material handling cost and inventory holding cost at warehouse. A temporal aggregation is the aggregation of shipment over time to make a single larger shipment, as opposed to multiple shipments, and gain the economy of scale. The temporal aggregation will make unit transportation cost smaller at the expense of lower responsiveness or larger inventory holding cost. Milk run distribution is the distribution of finished products from a manufacturer to multiple retailers using the same truck. The milk run distribution will allow retailers to order products in a smaller lot size, thereby lowering inventory holding cost without increasing the transportation cost. As many distribution strategies can be adopted, it is not clear when a supply chain manager should use to lower the total supply chain cost. Our research aims to provide managerial insight and guidelines for practitioners or business managers to follow without resorting to the optimization software at all time. By using one of strategies or the combination of strategies selectively, a supply chain structure is flexible and can quickly react to the changes in the supply chain. Also, when distribution planning is integrated with production planning, more total cost can be saved as the operations work seamlessly together. To provide the guideline of distribution strategies integrated with production plan, we develop a mathematical model called Mixed Integer Linear Programming Model, solve the model using optimization software called IBM ILOG CPLEX, and observe the optimal distribution strategies under various scenarios.

\section{Review of Literature}

Supply chain management aims to efficiently and effectively control the flow of materials from suppliers via many intermediate stages of supply chain such as a manufacturer and a warehouse to retailers or endcustomers. As the competition of business increases, not only the two companies compete but also the supply chains of the two companies compete. The coordination of companies in a supply chain such 
collaborative joint planning becomes common. The integration and collaboration in supply chain cannot be ignored because it affects operations of supply chain to fit with supply chain strategy (Graham, 2005). Logistic management, as a part of supply chain management, makes use of the flow of information, resource or knowledge to move product, part or raw material within supply chain to meet the requirements of customers or corporations. Logistics integration plays an importance role to seamlessly transfer products from producer to end customer (Caputo \& Mininno, 1996).Moreover, the information or knowledge is the key to link various stages of supply chain management. The idea of knowledge supply network (KSN) being used in the supply chain management to effectively and efficiently integrate suppliers, manufacturers, warehouses, and stores because a firm has to get the data, information and knowledge in order to distribute at the right quantities to the right locations and at the right time(Mak and Ramaprasad, 2003). Two major approaches of motor transportation mode are Less-Than-Truck Load (LTL) mode and Truck-Load (TL) mode. In LTL mode, the quantity of shipment is less than a truck load and the truck is then shared with other customers. Therefore, the truck will make multiple stops to transport the products to all the customers. In TL mode, the quantity of shipment is large enough to fill the whole truck capacity. Therefore, the truck will transport the product from a sender to a receiver without stopping at any locations. In our research, the TL mode from a manufacturer to a retailer is called direct shipment strategy and the LTL mode from a manufacturer to multiple retailers using the same truck is called milk run strategy. A milk run distribution is commonly used to support Just-In-Time (JIT) production because it allows small shipment sizes. It can reduce cost of transportation and inventory.

The manufacturer can use a truck to visit each supplier along the provided route to collect finished goods, or parts. After the truck has collected all of the parts, it will go back to the factory (Nemoto, Hayashi, \& Hashimoto, 2010). The milk run method is suitable when the density of part suppliers is high. The milk run method helps lower transportation cost due to the shipment consolidation, higher truck-load utilization, and lower number of trucks (Sadjadi, Jafari \& Amini, 2008). Another method of distribution is a direct shipment. The direct shipment uses a truck carrying shipment with nearly full capacity to deliver the products directly from supplier, or manufacturing location to a retail location (Puranik, 2010). This shipping does not pass the distribution center and the products do not be exchanged between vehicles. Typically, each product is made available at suppliers and delivered to retailer at constant production and consumption rates (Goldstein, 1997). Many industries such as high-tech, apparel, footwear as well as durables industries have adopted the direct shipment strategy. The main benefit of direct shipping method is the saving in transportation and storage costs. Also, it does not use a distribution center and, therefore, it does not waste time, money and distance (Bertazzi, 2008). With small truck size and fast transportation, the retailers can store fewer quantities of inventory. It provides efficiency as well as flexibility with no intermediate storage space, and the cost of insurance and maintenance (Cattani \& Souza, 2002). Our research is different from previous works in the literature. As many distribution strategies, i.e. direct shipment, milk run and temporal aggregation, can be mixed, the optimal strategies can be very flexible. Most researches will focus on one strategy. Also, we aim to provide guidelines for business managers but most researches will focus on developing an efficient heuristic procedure. The remaining of paper is organized as follows. Section 3 discusses the key assumptions and the model proposed. Section 4 tests the model to provide the managerial insights from studying the optimal solutions. Section 5 concludes the research and provides directions for future research.

Model: In this research, we study a supply chain with a manufacturer and multiple retailers. The manufacturer produces multiple products by using multiple production lines. Then, the products are sent to a warehouse to be stored until needed. Alternatively, the products can be transported the retailers directly. The manufacturer incurs holding cost at the warehouse, the production changeover cost and all the transportation costs including the truck fixed cost and distance-dependent costs. A retailer faces deterministic demands in a multi-period setting. When a retailer needs replenishment, the order is placed to the manufacturer. The manufacturer satisfies the demand using the distribution strategies: direct shipment from a loading area to the retailer, direct shipment from the warehouse to the retailer, the milk run shipment from the warehouse to all retailers requesting for replenishment using one truck. The retailer incurs the holding cost at the retail store and fixed reorder cost. Figure 1 shows the possible routes of distribution strategies when the number of retailers is five as an example. The numbers in circle show the node number. For example, the retailer at node 4 is called Retailer 4 . The manufacturer faces constraints from limited loading area space, the limited range of production quantity, limited total production time and limited truck capacity. The supply chain manager has to determine the optimal production planning, inventory replenishment planning, the optimal quantities of inventory kept at 
loading area, the warehouse and retail stores and the distribution strategies including the direct shipments from loading area or warehouse and the milk run shipment and truck routings.

Figure1: Flow of products at from production line to each retailer

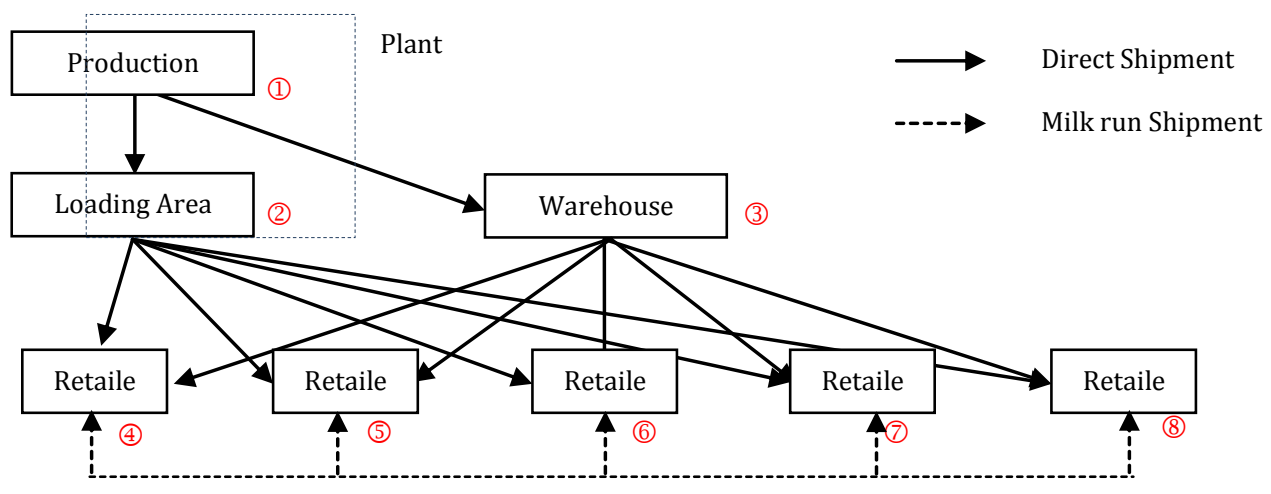

Based the problem description above, we formulate the problem as a Mixed Integer Linear Programming Model for solving the problem with the objective to minimize the total cost function. The total cost consists of fixed reorder cost in period $t$, fixed cost of truck, inventory holding cost, production changeover cost, transportation cost from the warehouse to each retailer, transportation cost from the loading area to each retailer, transportation cost from the production lines to the warehouse. The summary of variables and parameters is shown in Table 1.

Table 1: The parameters and decision variables

\begin{tabular}{|c|c|c|c|}
\hline \multicolumn{2}{|c|}{ Indexes } & \multicolumn{2}{|l|}{ Parameters } \\
\hline$i$ & Product index and $i \in \operatorname{Set} I=\{1, \ldots, I\}$ & $R c_{r}$ & $\begin{array}{l}\text { Fixed reorder cost of retailer } r \text { in } \\
\text { period } t\end{array}$ \\
\hline$j$ & Product index and $i \in \operatorname{Set} I=\{1, \ldots, I\}$ & $F C_{v}$ & Fixed cost of truck $v$ \\
\hline$t$ & $\begin{array}{l}\text { Production line index and } j \in \text { Set } J= \\
\{1, \ldots,\}\}\end{array}$ & $h_{n, i}$ & $\begin{array}{l}\text { Inventory holding cost of product } i \text { per } \\
\text { pallet per period at node } n\end{array}$ \\
\hline$n$ & Period index and $t \in$ Set $T=\{1, \ldots, T\}$ & $S c_{i, j}$ & $\begin{array}{l}\text { Setup cost incurred from changeover } \\
\text { from product } i \text { to } j\end{array}$ \\
\hline$v$ & Node index and $n \in \operatorname{Set} N=\{1, \ldots, N\}$ & $l_{o, d}$ & Cost from node $o$ to node $d$ \\
\hline$o$ & Truck index and $v \in$ Set $V=\{1, \ldots, V\}$ & $S_{r, i, t}$ & $\begin{array}{l}\text { Sale volume for product } i \text { at retailer } r \text { in } \\
\text { period } t\end{array}$ \\
\hline$d$ & $\begin{array}{l}\text { Original node index and } o \in \text { Set } R= \\
\{1, \ldots, R\}\end{array}$ & $\bar{M}$ & $\begin{array}{l}\text { Maximum number of space that } \\
\text { provided for loading area }\end{array}$ \\
\hline$r$ & $\begin{array}{l}\text { Destination node index and } d \in \operatorname{Set} R= \\
\{1, \ldots, R\}\end{array}$ & $M$ & Big number \\
\hline$i$ & Retailer index and $r \in \operatorname{Set} R=\{1, \ldots, R\}$ & $\bar{P}$ & $\begin{array}{l}\text { Maximum production capacity for all } \\
\text { production lines }\end{array}$ \\
\hline \multicolumn{2}{|c|}{ Decision Variables } & $\underline{P}$ & $\begin{array}{l}\text { Minimum production capacity for all } \\
\text { production lines }\end{array}$ \\
\hline $\operatorname{In} v_{n, i, t}$ & $\begin{array}{l}\text { Inventory of product } i \text { at node } n \text { at the } \\
\text { beginning of period } t\end{array}$ & $\operatorname{Pr}_{i, j}$ & $\begin{array}{l}\text { Production rate of product } i \text { at } \\
\text { production line } j\end{array}$ \\
\hline$S h_{i, o, d, t}$ & $\begin{array}{l}\text { Quantity of product } i \text { being shipped } \\
\text { from } o \text { to } d \text { in period } t\end{array}$ & $C t_{i, j}$ & $\begin{array}{l}\text { Changeover time of product } i \text { at } \\
\text { production line } j\end{array}$ \\
\hline$L_{j, t, i}$ & $\begin{array}{l}\text { Quantity of product } i \text { produced by } \\
\text { production line } j \text { and sent to loading } \\
\text { area in period } t\end{array}$ & $\bar{H}$ & $\begin{array}{l}\text { Number of available production time } \\
\text { (hours) per period per one production } \\
\text { line }\end{array}$ \\
\hline$A_{i, r, v, t}$ & $\begin{array}{l}\text { Quantity of product } i \text { shipped to } \\
\text { retailer } r \\
\text { using truck } v \text { in period } t\end{array}$ & TruckCapacity & The capacity of truck $v$ \\
\hline$P_{j, t, i}$ & $\begin{array}{l}\text { Production quantity of product } i \text { from } \\
\text { production line } j \text { in period } t\end{array}$ & TruckCapacity $_{D}$ & The capacity of a direct shipment truck \\
\hline$N D_{r, t}$ & $\begin{array}{l}\text { Number of direct shipment trucks } \\
\text { going to retailer } r \text { using in period } t\end{array}$ & PalletSize & The space of a pallet \\
\hline
\end{tabular}


(Assume to be only medium size truck)

$O r_{r, t} \quad 1$ if product is ordered by retailer $r$ via loading area in period $t, 0$ otherwise

$T r_{v, t} \quad 1$ if truck $v$ is used in period $t, 0$ otherwise

$f_{j, t, i} \quad 1$ if product $i$ is produced from production line $j$ in period $t, 0$ otherwise

$x_{v, o, d, t} \quad 1$ if truck $v$ travels from node $o$ to node $d$ in period $t, 0$ otherwise

$x_{v, o, d, t} \quad 1$ if truck $v$ is visited retailer $r$ in period $t, 0$ otherwise

$T r_{r, v, t} \quad 1$ if truck $v$ is used or visited any nodes in period $t, 0$ otherwise

$u_{n, v, t} \quad$ Arbitrary real numbers representing the sequence the nodes are being visited by truck $v$ in period $t$. It is used to prevent sub tours in the solutions using Miller-Tucker-Zimlin method.

According to the problem that we have, we formulate the problem as a Mixed Integer Linear Programming for solving the problem with the objective to minimize the total cost function. The total cost that we want to minimize consists of fixed reorder cost in period $t$, fixed cost of each sized truck, inventory holding cost, setup cost, transportation cost travelling from warehouse to each retailer, transportation cost travelling from loading area to each retailer, transportation cost travelling from production line to warehouse. We also have the constraints that state the limitation in each equation.

\section{Mathematical Model}

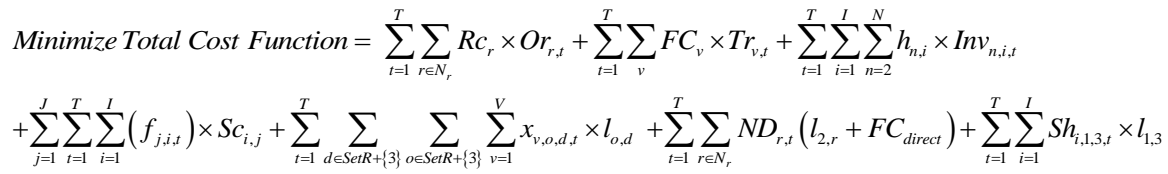

Subject To:

$\operatorname{Inv} v_{2, i, t}=\operatorname{Inv} v_{2, i, t-1}+\sum_{j=1}^{J} L_{j, t, i}-\sum_{d \in N_{r}} S h_{i, d, d, t}$ for all $i \in$ Set $i$ and $t \in \operatorname{Set} t$

$I n v_{r, i, t}=I n v_{r, i, t-1}+\operatorname{Sh} h_{i, 2, r, t}+\sum_{v=1}^{v} A_{i, r, v, t}-S_{r, i, t} \quad$ for all $i \in \operatorname{Set} i, t \in \operatorname{Set} t$, and $r \in \operatorname{Set} r$

(3)

$\operatorname{Inv} v_{3, i, t}=\operatorname{Inv} v_{3, i, t-1}+\operatorname{Sh} h_{i, 1,3, t}-\sum_{v=1}^{v} \sum_{r \in N_{t}} A_{i, r, v, t}$ for all $i \in$ Set $i$ and $t \in \operatorname{Set} t$

Inv $v_{n, 0}=0$ for all $i \in$ Set $i$

$L_{j, t, i} \leq P_{j, t, i}$ for all $i \in$ Set $i, j \in$ Set $j$, and $t \in$ Set $t$

(6)

$S h_{i, 1,3, t}=\sum_{j=1}^{J}\left(P_{j, t, i}-L_{j, t, i}\right)$ for all $i \in$ Set $i$, and $t \in \operatorname{Set} t$

(7)

$\sum_{i=1}^{I} I n v_{2, i, t} \times$ PalletSize $\leq \bar{M}$ for all $t \in$ Set $t$

(8)

$P_{j, t, i} \leq f_{j, t, i} \times \bar{P}$ for all $i \in$ Set $i, j$ Set $j$, and $t \in$ Set $t$

(9)

$P_{j, t, i} \geq f_{j, t, i} \times \underline{P}$ for all $i \in \operatorname{Set} i, j \in \operatorname{Set} j$, and $t \in \operatorname{Set} t$

$\sum_{i=1}^{L}\left(\frac{P_{j, t, i}}{\mathrm{Pr}_{i, j}}\right)+\sum_{i=1}^{I}\left(f_{j, t, i} \times C t_{i, j}\right) \leq \bar{H}$ for all $i \in \operatorname{Set} i$, and $j \in \operatorname{Set} j$

(11) 


$$
\begin{aligned}
& \sum_{o=2}^{3} \sum_{i=1}^{I} S_{i, o, r, t} \leq \text { Or } r_{r, t} \times M \text { for all } t \in \text { Set } t \\
& \sum_{r \in N_{r}} \sum_{i=1}^{I} A_{i, r, v, t} \leq \text { TruckCapacity }_{v} \times T r_{v, t} \text { for all } t \in \text { Set } t \text {, and } v \in \text { Set } v \\
& \sum_{i=1}^{I} A_{i, r, v, t} \leq \text { TruckCapacity }_{v} \times T r_{r, v, t} \text { for all } r \in \text { Set } N_{r}, t \in \text { Set } t \text {, and } v \in \text { Set } v \\
& \sum_{r \in N_{r}} T r_{r, v, t} \leq R \times T r_{v, t} \text { for all } t \in \text { Set } t \text {, and } v \in \text { Set } v
\end{aligned}
$$$$
\sum_{r \in N_{r}+\{3\}} x_{v, r, d, t}=T r_{d, v, t} \text { for all } d \in \operatorname{Set} N, t \in \operatorname{Set} t \text {, and } v \in \operatorname{Set} v
$$$$
\sum_{r=N_{r}+\{3\}} x_{v, d, r, t}=T r_{d, v, t} \text { for all } d \in \operatorname{Set} N, t \in \operatorname{Set} t \text {, and } v \in \operatorname{Set} v
$$

$$
\sum_{r=N_{r}+\{3\}} x_{v, r, 3, t}=\operatorname{Tr}_{v, t} \text { for all } t \in \operatorname{Set} t \text {, and } v \in \operatorname{Set} v
$$

$$
\sum_{r=N_{+}+\{3\}} x_{v, 3, r, t}=T_{v, t} \text { for all } t \in \text { Set } t \text {, and } v \in \operatorname{Set} v
$$

$$
\begin{aligned}
& \sum_{i=1}^{I} \frac{S h_{i, 2, r, t}}{\text { TruckCapacity }}{ }_{D} \\
& u_{3, v, t}=1 \text { for all } t \in \text { Set } t \text {, and } v \in \text { Set } v
\end{aligned}
$$

$$
2 \leq u_{o, v, t} \leq n \text { where } n=\left|N_{r} \cup\{3\}\right| \text { for all } o \in \operatorname{Set} N_{r}, v \in \text { Set } v \text {, and } t \in \text { Set } t
$$

$u_{o, v, t}-u_{d, v, t}+1 \leq n \times\left(1-x_{v, o, d, t}\right)$ where $n=\left|N_{r} \cup\{3\}\right|$ for all $o \in \operatorname{Set}_{r}$, all $d \in \operatorname{Set} N_{r}, v \in \operatorname{Set} v$, and $t \in \operatorname{Set} t$

The meaning of each equation can be summarized as follows. Equation (1) specifies the total costs. Equations (2)-(4) establish the relationship between the inventory in period $t$ and $t+1$, the quantities of inbound shipments, and the quantities of outbound shipments (or sales quantities) at loading area, warehouse and retail stores, respectively. Equation (5) sets up initial inventory at all locations to be zero. Equation (6) limits the quantities sent to loading area to be fewer than the production quantities. Equation (7) calculates the quantities to be stored at the warehouse. Equation (8) limits the number of products to be kept at loading area. Equations (9) and (10) set up the lower bound and the upper bound for production quantities. Equation (11) limits the total production time and changeover times for each production line to be less than the total production time available in a period. Equation (12) links the shipment quantities to reorder decision. Equations (13) and (14) set up the relationship between the milk run shipments with truck usage variables and also set up the capacity of milk run shipment. Equations (16)-(19) conserve the truck inflow decision and truck outflow decision and also link them with the truck usage variables. Equation (20) calculates the number of trucks used for direct shipment from loading area. Equations (21)-(23) are the standard Miller-Tucker-Zemlinsubtour-elimination constraints.

\section{Numerical Experiment and Results}

We have conducted the numerical experiments by using an example with 1 production line, 1 product, 5 retailers and 4 periods. The problem is solved to optimality using IBM ILOG CPLEX version 12 . We assume there are three truck sizes: small, medium and large. The numbers of small, medium and large trucks available at the warehouse are 4, 3, and 3 trucks, respectively. The number of trucks at the plant is unlimited. The travel cost from the production line to the warehouse is 5 per pallet. The number of retailers of five allows us to examine in details the optimal distribution strategies adopted in each period and also allow some flexibility to use the mixed distribution strategies at the same time. Table 2 shows the values of parameters in the base case. 
Table 2: The parameters of base case used in the experiments

\begin{tabular}{|c|c|c|c|c|c|c|c|c|c|c|c|c|c|c|}
\hline $\begin{array}{l}\text { Fixed } \\
\text { Cost } \\
\text { for }\end{array}$ & $\begin{array}{l}\text { Fixed } \\
\text { Cost } \\
\text { for }\end{array}$ & $\begin{array}{l}\text { Fixed } \\
\text { Cost } \\
\text { for }\end{array}$ & $\begin{array}{l}\text { Unit } \\
\text { Holdin } \\
\text { g cost }\end{array}$ & $\begin{array}{l}\text { Chang } \\
\text { e-over } \\
\text { cost }\end{array}$ & $\begin{array}{l}\text { Travel } \\
\text { cost } \\
\text { betwe }\end{array}$ & $\begin{array}{l}\text { Travel } \\
\text { cost } \\
\text { betwe }\end{array}$ & $\begin{array}{l}\text { Travel } \\
\text { cost } \\
\text { betwe }\end{array}$ & $\begin{array}{l}\text { Travel } \\
\text { cost } \\
\text { betwe }\end{array}$ & $\begin{array}{l}\text { Travel } \\
\text { cost } \\
\text { betwe }\end{array}$ & $\begin{array}{l}\text { Travel } \\
\text { cost } \\
\text { betwe }\end{array}$ & $\begin{array}{l}\text { Travel } \\
\text { cost } \\
\text { betwe }\end{array}$ & $\begin{array}{l}\text { Travel } \\
\text { cost } \\
\text { betwe }\end{array}$ & $\begin{array}{l}\text { Travel } \\
\text { cost } \\
\text { betwe }\end{array}$ & $\begin{array}{l}\text { Travel } \\
\text { cost } \\
\text { betwe }\end{array}$ \\
\hline $\begin{array}{l}\text { Small } \\
\text { Truck }\end{array}$ & $\begin{array}{l}\text { Mediu } \\
\text { m } \\
\text { Truck }\end{array}$ & $\begin{array}{l}\text { Large } \\
\text { Truck }\end{array}$ & & & $\begin{array}{l}\text { en } 2 \\
\text { and } \\
\text { node } 4\end{array}$ & $\begin{array}{l}\text { en } 2 \\
\text { and } \\
\text { node } 5\end{array}$ & $\begin{array}{l}\text { en } 2 \\
\text { and } \\
\text { node } 6\end{array}$ & $\begin{array}{l}\text { en } 2 \\
\text { and } \\
\text { node } 7\end{array}$ & $\begin{array}{l}\text { en } 2 \\
\text { and } \\
\text { node } 8\end{array}$ & $\begin{array}{l}\text { en } 3 \\
\text { and } \\
\text { node } 4\end{array}$ & $\begin{array}{l}\text { en } 3 \\
\text { and } \\
\text { node } 5\end{array}$ & $\begin{array}{l}\text { en } 3 \\
\text { and } \\
\text { node } 6\end{array}$ & $\begin{array}{l}\text { en } 3 \\
\text { and } \\
\text { node } 7\end{array}$ & $\begin{array}{l}\text { en } 3 \\
\text { and } \\
\text { node } 8\end{array}$ \\
\hline 1500 & 2000 & 4000 & 20 & 500 & 40 & 80 & 120 & 160 & 200 & 20 & 40 & 60 & 80 & 100 \\
\hline $\begin{array}{l}\text { Travel } \\
\text { cost } \\
\text { betwe } \\
\text { en } 4 \\
\text { and } \\
\text { node } 5\end{array}$ & $\begin{array}{l}\text { Travel } \\
\text { cost } \\
\text { betwe } \\
\text { en } 4 \\
\text { and } \\
\text { node } 6\end{array}$ & $\begin{array}{l}\text { Travel } \\
\text { cost } \\
\text { betwe } \\
\text { en } 4 \\
\text { and } \\
\text { node } 7\end{array}$ & $\begin{array}{l}\text { Travel } \\
\text { cost } \\
\text { betwe } \\
\text { en } 4 \\
\text { and } \\
\text { node } 8\end{array}$ & $\begin{array}{l}\text { Travel } \\
\text { cost } \\
\text { betwe } \\
\text { en } 5 \\
\text { and } \\
\text { node } 6\end{array}$ & $\begin{array}{l}\text { Travel } \\
\text { cost } \\
\text { betwe } \\
\text { en } 5 \\
\text { and } \\
\text { node } 7\end{array}$ & $\begin{array}{l}\text { Travel } \\
\text { cost } \\
\text { betwe } \\
\text { en } 5 \\
\text { and } \\
\text { node } 8\end{array}$ & $\begin{array}{l}\text { Travel } \\
\text { cost } \\
\text { betwe } \\
\text { en } 6 \\
\text { and } \\
\text { node } 7\end{array}$ & $\begin{array}{l}\text { Travel } \\
\text { cost } \\
\text { betwe } \\
\text { en } 6 \\
\text { and } \\
\text { node } 8\end{array}$ & $\begin{array}{l}\text { Travel } \\
\text { cost } \\
\text { betwe } \\
\text { en } 7 \\
\text { and } \\
\text { node } 8\end{array}$ & $\begin{array}{l}\text { Retail } \\
\text { er } \\
\text { Dema } \\
\text { nd }\end{array}$ & $\begin{array}{l}\text { Chang } \\
\text { e-over } \\
\text { Time }\end{array}$ & $\begin{array}{l}\text { Small } \\
\text { Truck } \\
\text { Capaci } \\
\text { ty }\end{array}$ & $\begin{array}{l}\text { Mediu } \\
\text { m } \\
\text { Truck } \\
\text { Capaci } \\
\text { ty }\end{array}$ & $\begin{array}{l}\text { Large } \\
\text { Truck } \\
\text { Capaci } \\
\text { ty }\end{array}$ \\
\hline 10 & 20 & 30 & 40 & 10 & 20 & 30 & 10 & 20 & 10 & 90 & 5 & 40 & 70 & 100 \\
\hline
\end{tabular}

We have run the base case scenario and found the following distribution strategies. The decisions for period 1 and 3 are the same and the decisions for period 2 and 4 are the same. At the period 1 and 3 , the manufacturer will deliver a total of 110 units to all retailers. 90 pallets are to be used in period 1 and another 20 pallets are to be kept at retailer inventory. To retailers 4, 5, 6, and 7, one medium truck using direct shipment from loading area carries 70 pallets and one small truck using direct shipment from warehouse carries 40 pallets. As the number of small trucks available is only 4 at the warehouse, retailer 8 is sent by direct shipment using two medium trucks from loading area. In period 2 and 4 , as the demand for each period is 90 pallets, the quantity of shipment required in these periods is only 70 pallets because the remaining 20 pallets of demand are satisfied by inventory kept from last period. By keeping 20 pallets of inventory at retailer, the transportation cost can be reduced in these periods. Figure 2 and 3 show the distribution strategies explained. In the base case, we observe the use of direct shipment strategies from both loading area and warehouse and the temporal aggregation of shipment by sending more than retailers need.

Figure 2: Flow of products from production line to each retailer in period 1 and 3 for the base case

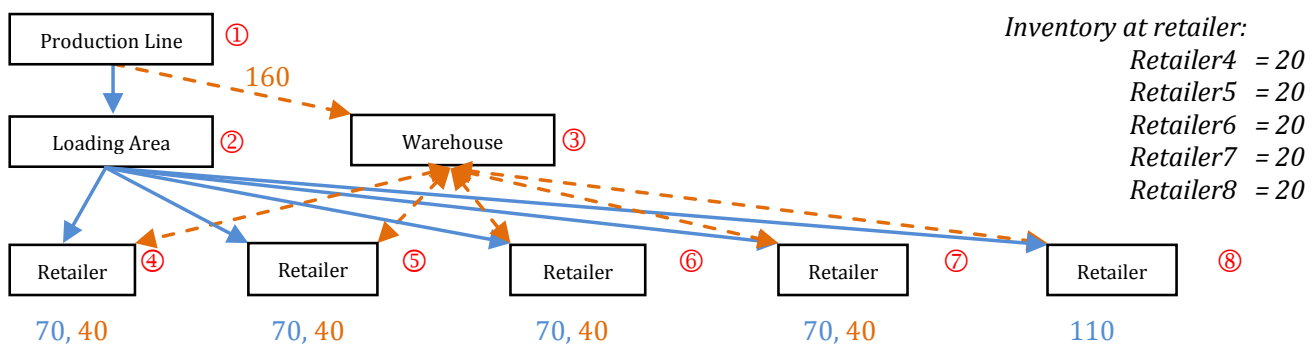

Figure 3: Flow of products from production line to each retailer in period 2 and 4 for the base case

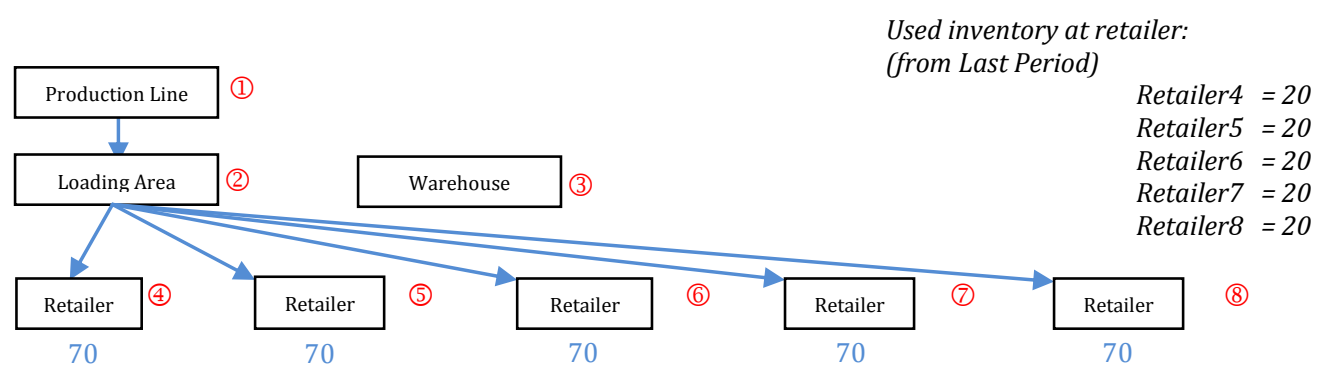

In the next experiment, the effect of demand size is tested to compare the optimal distribution strategies with that of base case. We test four more cases of demand size. However, in this abridged paper, only the insights and observed strategies will be discussed without showing the detailed strategies as shown in the base case. Table 3 shows the number of demand (in pallets) at each retailer for all cases and the optimal strategies observed. As we see from Table 3, the temporal aggregation is always used. This means the size of some shipment is larger than the demand because the shipments are aggregated before being sent to the retailer. The excess quantities are kept at retail store as inventory even with the holding cost charged at retail stores. The inventory is usually not enough to fulfill $100 \%$ of demand in the following period but it is usually a fraction of demand enough to prevent using additional truck in the later period. Thus, inventory at the retail store is the key tool to lower transportation costs. Milk run strategy is only optimal to use with the demand is very small compared to truck capacity. When the demand is small, instead of using milk run to combine shipments from multiple retailers, the optimal strategy chooses to 
combine the shipment over time or use temporal aggregation. Whenever possible, the direct shipment strategy is employed either from the warehouse or loading area.

Table 3: The number of demand in pallets at each retailer for all cases and the observed optimal strategies

\begin{tabular}{lll}
\hline Cases & $\begin{array}{c}\text { Demand at Retailers } \\
\text { 4-8 (Pallets) }\end{array}$ & Observed Strategy \\
\hline Very small Demand & 3 & milk run strategy and temporal aggregation \\
Small Demand & 30 & direct shipment strategy and temporal aggregation \\
Base Case Demand & 90 & direct shipment strategy and temporal aggregation \\
Medium Demand & 123 & direct shipment strategy and temporal aggregation \\
Large Demand & 378 & direct shipment strategy and temporal aggregation \\
\hline
\end{tabular}

Next, the effect of holding cost is tested to compare the optimal distribution strategies with that of base case. We test three cases of holding cost. Table 4 shows the unit holding cost charged at all retail stores and warehouse, and the observed optimal strategies. The temporal aggregation is used in low holding cost and base case. With small holding cost, the large shipment is sent to retail stores and the excess quantities are kept as inventory. In the base case, the quantities of inventory reduce from the first case. With the large holding cost, the inventories kept at any places are all zero to avoid paying for the holding cost. Then, without the inventory, the shipped quantities must perfectly match the demand in each period. Most of demands are satisfied by the direct shipment. However, the remaining demand, which is typically less than the truck load, is matched by the shipments from a milk run truck visiting a few retailers. By having two modes of shipments, direct shipment and milk run methods, the supply chain is more flexible and can use both methods to help match the demand with the shipments if needed.

Table 4: the unit holding cost charged at all retail store and warehouse and the observed optimal strategies

\begin{tabular}{lll}
\hline Cases & $\begin{array}{l}\text { Holding cost per pallet } \\
\text { per period }\end{array}$ & Observed Strategy \\
\hline Low & 7 & direct shipment strategy and temporal aggregation \\
Base Case & 20 & direct shipment strategy and temporal aggregation \\
High & 245 & direct shipment(mostly) and milk run strategies \\
\hline
\end{tabular}

Lastly, the effect of fixed truck cost is tested to compare the optimal distribution strategies with that of base case. We test three cases of fixed truck cost. Table 5 shows the fixed truck cost for three scenarios. Table 6 shows the number of trucks used for each size and the observed optimal strategies.

Table 5: The fixed cost for all sizes of trucks and the observed optimal strategies

\begin{tabular}{lllll}
\hline Cases & $\begin{array}{l}\text { Fixed cost for small } \\
\text { truck }\end{array}$ & $\begin{array}{l}\text { Fixed cost } \\
\text { medium truck }\end{array}$ & for $\begin{array}{l}\text { Fixed cost for Large } \\
\text { truck }\end{array}$ \\
\hline Low Fixed Truck & 356 & 1540 & 2555 \\
Cost & & & \\
Base Case & 1500 & 2000 & 4000 \\
High Fixed Truck & 2500 & 3500 & 5000 \\
Cost & & & \\
\hline
\end{tabular}

Table 6: The total number of trucks used and the observed optimal strategies

\begin{tabular}{lllll}
\hline Cases & $\begin{array}{l}\text { Total number } \\
\text { of } \\
\text { small trucks }\end{array}$ & $\begin{array}{l}\text { Total number of } \\
\text { medium trucks }\end{array}$ & $\begin{array}{l}\text { Total } \\
\text { number of } \\
\text { large trucks }\end{array}$ & Observed Strategy \\
\hline $\begin{array}{l}\text { Low Fixed Truck } \\
\text { Cost }\end{array}$ & 10 & 17 & 3 & $\begin{array}{l}\text { direct shipment(mostly) and } \\
\text { milk run strategy with } \\
\text { temporal aggregation }\end{array}$ \\
Base Case & 8 & & 0 & $\begin{array}{l}\text { direct shipment strategy and } \\
\text { temporal aggregation } \\
\text { direct shipment strategy and } \\
\text { temporal aggregation }\end{array}$ \\
\hline $\begin{array}{l}\text { High Fixed Truck } \\
\text { Cost }\end{array}$ & 8 & 22 & 3 & \\
\hline
\end{tabular}


From Table 6, the temporal aggregation is used for all cases. However, with low fixed truck cost, the quantities of inventory are smaller. The direct shipment is used to carry most of the shipment. Many small trucks are used with milk run strategy to carry small quantity of shipment to try to match the shipment with demand, thus reducing the number of inventory at retail store. As the truck cost is higher, it is more economical to use larger size trucks to carry larger quantities of product and store at retailers. Again, by having two modes of shipments, direct shipment and milk run methods, the supply chain is more flexible and can use both methods to help match the demand with the shipments if needed. Also, even though the milk run shipment is used, it is not the main mode of transportation because it carries just a small quantity to help match the demand better.

\section{Conclusion}

We study a supply chain system consisting of a manufacturer owning multiple production lines and a warehouse, and multiple retailers buying from the manufacturer. The manufacturer can choose whether to send the product to the retailers directly from loading area using direct shipment or send the product to be stored at the warehouse. If the demand is satisfied from the warehouse, the company can choose the logistics strategy. The company can send the product from the warehouse to a retailer using a direct shipment mode or using milk run mode. A mixed integer programming model is constructed to help analyze the optimal distribution strategies. We conduct numerical experiments and then analyze the results to extract the managerial insight for practitioners. We found that by allowing both milk run and direct shipment strategies, the supply chain can customize the distribution strategies to satisfy demand at a lower cost. We observe that only when the demand is very small, the pure milk run strategy is used. When holding cost is high and fixed truck cost is low, the milk run strategy is used with the direct shipment. When milk run strategy is used, it carries only a small quantity of shipment so that the demand can be closely matched or an additional truck cost can be prevented. Also, the milk run strategy is only observed where the locations of retail stores are near. We found that, for most of the times, the direct shipment carries the largest load either from the loading area or warehouse. Also, the temporal shipment aggregation is observed almost every case. That is, it is beneficial that retail stores have some capacity to hold inventory because the transportation cost can be lowered using combined shipment. In the future research, a larger set of numerical experiment will be conducted to better understand the complicated optimal decisions. A statistical analysis such as a regression model will be used to find the factors affecting the optimal strategies adopted.

\section{References}

Bertazzi, L. (2008). Analysis of Direct Shipping Policies in an Inventory-Routing Problem with Discrete Shipping Times. Management Science, 54(4), 748-762.

Caputo, J. \& Mininno, M. (1996). Internal, vertical, and horizontal logistics integration. International Journal of Physical Distribution \& Logistics Management, 26, 64-90.

Cattani, K. \& Souza, G. C. (2002).Inventory rationing and shipment flexibility alternatives for direct market firms. Production and Operations Management, 11, 441-457.

Goldstein, S. (1997). M.S. Distributing trying direct-shipment approach. Billboard, 109(41), 12-100.

Graham, C. S. (2005). Integrating the Supply Chain. International Journal of Physical Distribution \& Logistics Management, 19, 3-8.

Lai, C. L. \& Lee, W. B., \& Ip, W. H. (2003). A study of system dynamics in just-in-time logistics. Journal of materials Processing Technology, 138, 265-269.

Mak, K. T. \& Ramaprasad, A. (2003). Knowledge Supply Network. The Journal of the Operational Research Society, 54(2), 175-183.

Nemoto, T., Hayashi, K. \& Hashimoto, M. (2010). Milk-Run logistics by Japanese automobile manufacturers in Thailand. Procedia Social and Behavioral Sciences, 2, 5980-5989.

Puranik, A. S. (2010). Direct/Indirect Delivery Decisions in a Collaborative Supply Distribution Network. West Lafayette, Indiana: UMI Dissertation Publishing.

Sadjadi, S. J., Jafari, M. \& Amini, T. (2008). A new mathematical modeling and a genetic algorithm search for milk run problem (an auto industry supply chain case study). Int J AdvManufTechnol, 44, 194200. 